The Lancet Infectious Diseases (2015) vol 15, pp 757-758

\title{
Schistosomiasis reaches Europe
}

Jérôme Boissier1, Hélène Moné1, Guillaume Mitta1, M Dolores Bargues2, David Molyneux3, Santiago Mas-Coma2

1-Univ. Perpignan Via Domitia, IHPE UMR 5244, CNRS, IFREMER, Univ. Montpellier, F-66860 Perpignan?

France

2-Departamento de Parasitologia, Facultad de Farmacia, Universidad de Valencia, Burjassot, Valencia, Spain

3- Department of Parasitology, Liverpool School of Tropical Medicine, Liverpool, UK boissier@univ-perp.fr

An outbreak of urogenital schistos omiasis has been detected in Europe, with patients aff ected in France, ${ }^{1,2}$ Germany, ${ }^{1,2}$ and Italy. The infection originated in Corsica, in a river north of Porto-Vecchio, a popular tourist destination (fi gure). The introduction of schistosomiasis is believed to be associated with infected people arriving from a region endemic for the exclusively African parasite, Schistosoma haematobium and disseminating parasite eggs through their urine into snail breeding sites along the river. Subsequent infection of freshwater planorbid snails, Bulinus truncatus, which are present throughout Corsica, ${ }^{3}$ then occurred, showing the compatibility of the imported parasite with the local snail.

Transmission seems to have occurred since 2011. The late disc overy of this situation in May, 2014, was related to misdiagnosis of haematuria in patients infected in previous years who had never been to Africa and thus the absence of trips to Africa being listed in their case histories. This outbreak is unexpected; the last recorded case of $S$ haematobium transmission in Europe was in southern Portugal where the fi nal patient was cured in 1967. Urogenital schistosomiasis was then declared eliminated in Europe and not viewed as an infection that presented a risk of introduction into the continent.

This outbreak raises several questions. Did people who were initially infected return and urinate in the same river every year, con tributing to the maintenance of the focus? Analyses suggest that both tourists and local residents have become infected. Has climate change in southern Europe allowed an over wintering transmission to proceed uninterrupted in recent years? Will changes in temperature and rainfall in the Mediterranean aff ect freshwater snail-borne diseases? ${ }^{4}$ Snail-borne infections have not been considered in a survey mapping climate change vulnerabilities to infectious diseases in Europe. ${ }^{5}$

Molecular studies on the Corsican schistosome strain have shown that, in addition to pure $S$ haematobium, most of the eggs collected from patients are hybrids of $\mathrm{S}$ haematobium and the livestock species Schistosoma bovis. This unexpected fi nding sugg ests that either several introd uctions from human beings infect ed with the diff erent strains of $S$ haematobium occurred, or that hybridisation has occurred in Corsica. Furthermore, the involvement of such a hybrid form has many repercussions. It increases the range of potential vectors, since the widespread Planorbarius metidjensis snail transmits $\mathrm{S}$ bovis, thus increasing the risk of dis semination to Portugal, Spain, and Italy. 
Figure: Focus of freshwater transmission of urogenital schistosomiasis frequented by tourists in Corsica This river is visited by 3000-5000 people every day during the summer season.

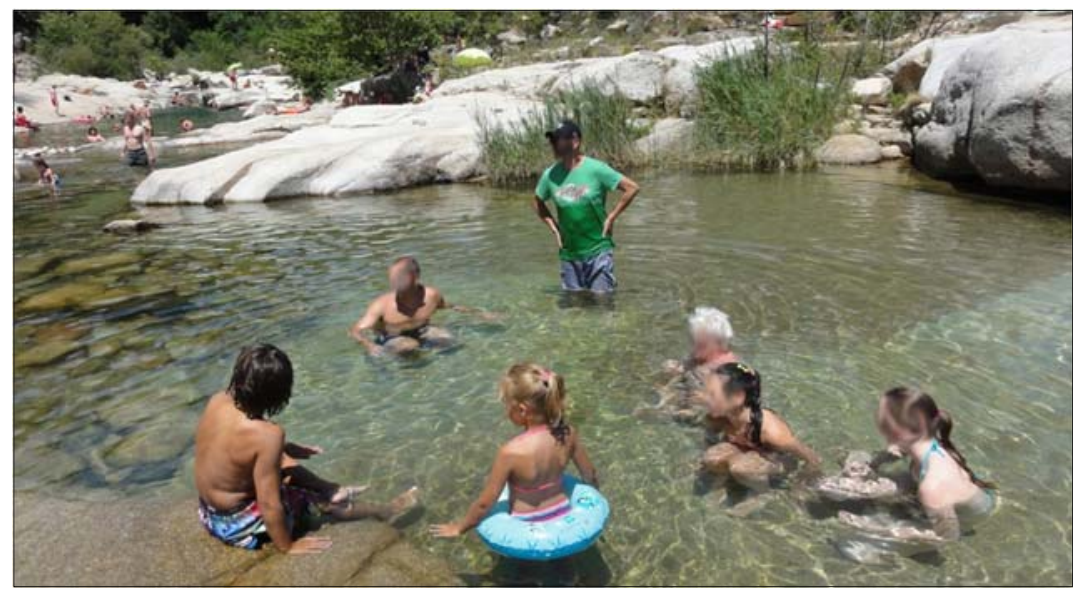

\section{COMMENT}

Additionally, the potential role of other livestock species should be assessed in Corsica, where goat, sheep, and cattle husbandry is a largely uncontrolled farming activity. Foci of $S$ bovis are known in Corsica, ${ }^{6}$ Sardinia, ${ }^{7}$ Portugal, ${ }^{8}$ and Spain. ${ }^{8}$ The adaptation of a human infective African hybrid schistosome to local European livestock represents a serious threat. Little is known about of the pathology of $S$ haematobium$S$ bovis hybrids in human beings. The fact that hybrid eggs were found in the urine of patients infected in Corsica, and molluscs were success fully infected by larval stages obtained from these eggs (Boissier J, unpublished), suggests these hybrids can perpetuate the parasite cycle. However, we do not yet know their virulence or the epidemiological consequences.

A European initiative is being launched, coo rdinated by the Parasitic Disease Threat Quick Response Committee of the European Federation of Parasitol ogists, to assess the questions posed by this outbreak; evaluate the potential risk in Portugal, Spain, and Italy; and establish a European Network of specialists on snail vectors and snail-borne diseases to assist the European Centre for Disease Control and Prevention in its preparedness activities.

There is much to learn from this outbreak. In the WHO Roadmap 2015-20 to overcome the global conseq uences of neglected tropical diseases, in addition to schistos omi asis, other snail-borne helminthiases are included within the food-borne trematodiases: worldwide fascioliasis is an emerging threat as a result of climate and global changes, ${ }^{9}$ and Opisthorchis felineus is also emerging in Europe. ${ }^{10}$ At the WHO World Health Day on April 7, 2014, the WHO DirectorGeneral Dr Margaret Chan emphasised the increasing concern about the eff ect of climate change on these vector-borne infect ions. This schistosomiasis outbreak, together with the emergence of fascioliasis and $O$ felineus in Europe, draw attention to the need to recognise that, in addition to mosquito-borne infections, snail vectors and snail-borne diseases are a new public health threat in Europe. 
Funds for fi eldwork were provided by WHO headquarters (Geneva, Switzerland). The content is solely the responsibility of the authors, although it was agreed with the WHO Department of Control of Neglected Tropical Diseases. The funders had no role in study design, data collection, analysis, or interpretation. We declare no competing interests.

1 Berry A, Moné H, Iriart X, et al. Schistosomiasis haematobium, Corsica, France. Emerg Infect Dis 2014; 20: 1595-97.

2 Holtfreter MC, Moné H, Müller-Stöver I, et al. Schistosoma haematobium infections acquired in Corsica, France, August 2013. EuroSurveillance 2014; 19: 20821.

3 Doby JM, Rault B, Deblock S, Chabaud A. Bulins et bilharziose en Corse. Répartition, frtéquence et biologie de "Bulinus truncatus". Ann Parasitol Hum Comp 1966; 41: 33749.

4 Mas-Coma S, Valero MA, Bargues MD. Climate change eff ects on trematodiases, with emphasis on zoonotic fascioliasis and schistosomiasis. Vet Parasitol 2009; 163: 264-80.

5 Semenza JC, Suk JE, Estevez V, et al. Mapping climate change vulnerabilities to infectious diseases in Europe. Environ Health Perspect 2012; 120: 385-92.

6 Brumpt E. Cycle évolutif complet de Schistosoma bovis, infection naturelle en Corse et infection expérimentale de Bulinus contortus. Ann Parasitol Hum Comp 1930; 8: 17-50.

7 Sadun EH, Biocca E. Intradermal and fl uorescent antibody tests on humans exposed to Schistosoma bovis cercariae from Sardinia. Bull WHO 1962; 27: 810-14.

8 Ramajo Martín V. Contribución al estudio epizootiológico de la esquistosomiasis bovina (Schistosoma bovis) en la provincia de Salamanca. An Fac Vet León 1972; 18: 151-214.

9 Mas-Coma S, Valero MA, Bargues MD. Fasciola, lymnaeids and human fascioliasis, with a global overview on disease transmission, epidemiology, evolutionary genetics, molecular epidemiology and control. Adv Parasitol 2009; 69: 41-146.

10 Pozio E, Armignacco O, Ferri F, et al. Opisthorchis felineus, an emerging infection in Italy and its implication for the European Union. Acta Trop 2013; 126: 54-62. 